\title{
A facile post-synthetic modification method to improve hydrothermal stability and CO2 selectivity of CuBTC metal- organic framework
}

DOI:

10.1021/acs.iecr.5b04217

\section{Document Version}

Accepted author manuscript

Link to publication record in Manchester Research Explorer

Citation for published version (APA):

Al-Janabi, N., Deng, H., Borges, J., Liu, X., Garforth, A., Siperstein, F., \& Fan, X. (2016). A facile post-synthetic modification method to improve hydrothermal stability and CO2 selectivity of CuBTC metal-organic framework. Industrial \& Engineering Chemistry Research, 55(29), 7941-7949. https://doi.org/10.1021/acs.iecr.5b04217

\section{Published in:}

Industrial \& Engineering Chemistry Research

\section{Citing this paper}

Please note that where the full-text provided on Manchester Research Explorer is the Author Accepted Manuscript or Proof version this may differ from the final Published version. If citing, it is advised that you check and use the publisher's definitive version.

\section{General rights}

Copyright and moral rights for the publications made accessible in the Research Explorer are retained by the authors and/or other copyright owners and it is a condition of accessing publications that users recognise and abide by the legal requirements associated with these rights.

\section{Takedown policy}

If you believe that this document breaches copyright please refer to the University of Manchester's Takedown Procedures [http://man.ac.uk/04Y6Bo] or contact uml.scholarlycommunications@manchester.ac.uk providing relevant details, so we can investigate your claim.

\section{OPEN ACCESS}




\title{
A Facile Post-Synthetic Modification Method To Improve Hydrothermal Stability and $\mathrm{CO}_{2}$ Selectivity of CuBTC Metal-Organic Framework
}

\author{
Nadeen Al-Janabi, Haoran Deng, Jayane Borges, Xufei Liu, Arthur Garforth, Flor R. Siperstein, \\ and Xiaolei Fan*
}

School of Chemical Engineering and Analytical Science, The University of Manchester, Oxford Road, Manchester M13 9PL, United Kingdom

Supporting Information

ABSTRACT: Practical applications require hydrothermally stable metal-organic frameworks (MOFs). Achieving stable MOFs in the presence of water or humidity is challenging, especially for MOFs with open metals sites (OMSs) due to the high affinity of water molecules toward OMSs. A straightforward solution to tackling this problem is to protect OMSs in the porous structure of MOFs. A facile post-synthetic modification (PSM) method for the synthesis of molecular glycine-doped CuBTC MOF (BTC = benzene-1,3,5-tricarboxylic acid) was developed in this study. Developed materials, i.e.,
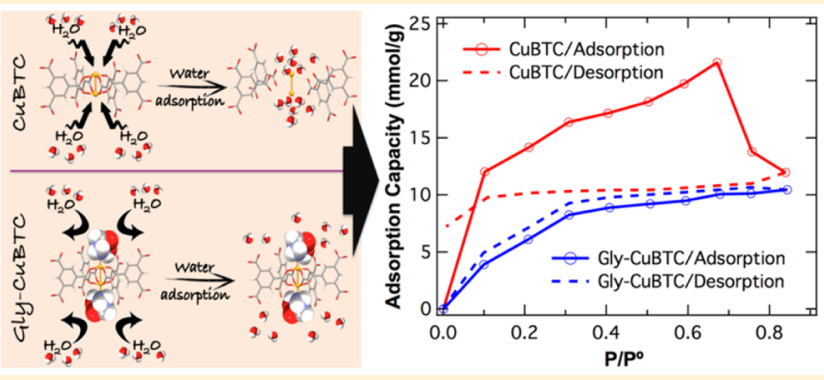
Gly-CuBTC MOFs, were characterized using various characterization techniques and evaluated using single-component gas $\left(\mathrm{CO}_{2}\right.$ and $\left.\mathrm{N}_{2}\right)$ adsorption and dynamic water vapor adsorption experiments. The economical dopant of molecular glycine with amine and a carboxyl group was found to be able to saturate OMSs in the parent CuBTC MOF, leading to improved hydrothermal stability and $\mathrm{CO}_{2}: \mathrm{N}_{2}$ selectivity. It was also found that the adsorption capacity, $\mathrm{CO}_{2}: \mathrm{N}_{2}$ selectivity, and hydrothermal stability of Gly-CuBTC MOFs depend on the percentage of saturation of OMSs in the parent MOF.

\section{INTRODUCTION}

Metal-organic framework (MOFs), ${ }^{1}$ as versatile and promising adsorbents, have attracted much attention for $\mathrm{CO}_{2}$ capture due to their high adsorption capacity, large specific surface area, and tunable structure. ${ }^{2,3}$ Open metal sites (OMSs) in certain MOFs, e.g., unsaturated copper centers in CuBTC MOF (BTC = benzene-1,3,5-tricarboxylic acid), ${ }^{4}$ are believed to be attractive features for attracting small gas molecules, ${ }^{5-8}$ especially for polar molecules such as water. Considering the practical application of MOFs with OMSs, the presence of water or humidity is inevitable, such as the post-combustion carbon capture from flue gases, where $5-7$ vol $\%$ water vapor is present., 10

CuBTC MOF is one of the most well-studied MOFs with $\mathrm{OMSs}^{10-18}$ since its discovery at the end of the 20th century. ${ }^{19}$ CuBTC is very sensitive to moisture, and water-CuBTC interactions have been investigated in simulation ${ }^{20-22}$ and experimental studies. ${ }^{10,23-29}$ The poor hydrothermal stability of CuBTC MOF has been proven to be linked directly with the vulnerability of OMSs in the framework to water molecules. The strong water affinity for OMSs results in the aggregation of water molecules near OMSs under continuous hydration and can lead to the displacement of BTC ligands from OMSs. ${ }^{10,25,30,31}$ Various approaches have been developed to modify CuBTC for selective gas adsorption and catalysis mainly by ligand functionalization. ${ }^{32-37}$ For example, Cai et al. ${ }^{32,35}$ demonstrated the possibility of using the alkyl-functionalized BTC to construct CuBTC derivatives. In comparison with the original CuBTC MOF, the alkyl-functionalized CuBTC derivatives showed comparable uptakes of $\mathrm{CO}_{2}$ and $\mathrm{CH}_{4}$ at pressures up to 5 bar and significantly lower water adsorption due to the introduction of hydrophobic functional groups. Another effective method of coating MOFs using hydrophobic polydimethysiloxane (PDMS) was also suggested. ${ }^{88}$ This approach involved the chemical vapor deposition of a hydrophobic silicon layer over the surface of MOFs (including CuBTC) at $235^{\circ} \mathrm{C}$ to enhance their moisture resistance. Though these approaches demonstrated the effectiveness toward improving the moisture stability of resulting materials, they either involve tedious synthetic procedures for functionalizing ligands or complex apparatus and harsh conditions for materials modification hindering their practical application.

Post-synthetic modification (PSM) of MOFs, on the other hand, is an attractive approach for facile functionalization of

Special Issue: International Conference on Carbon Dioxide Utilization 2015

Received: November 6, 2015

Revised: $\quad$ March 8, 2016

Accepted: March 16, 2016 


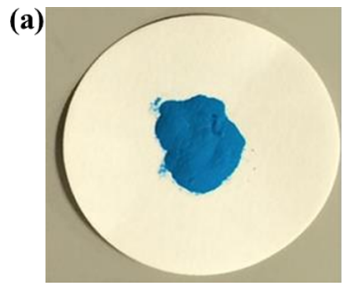

As-made CuBTC

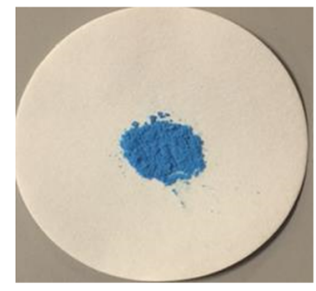

As-made Gly-CuBTC

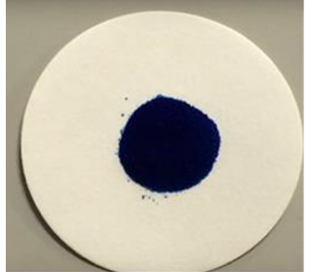

Activated CuBTC

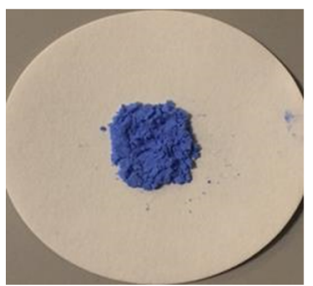

Activated Gly-CuBTC

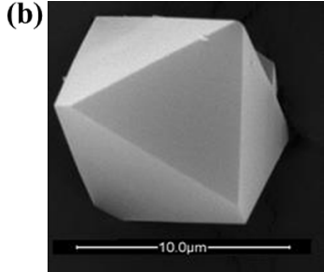

CuBTC

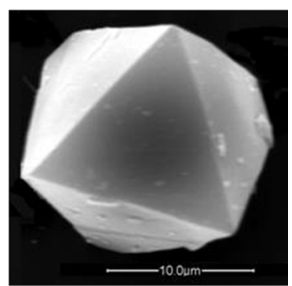

Gly-CuBTC

Figure 1. (a) As-made and activated CuBTC and Gly-CuBTC samples and (b) SEM images of CuBTC and Gly-CuBTC crystals.

MOFs. ${ }^{39-42}$ Luo et al. developed a PSM method to graft OMSs in CuBTC MOF using an amino-functionalized basic ionic liquid (ABIL-OH) for enhancing the selectivity in liquid-phase catalytic Knoevenagel condensation reactions. ${ }^{39}$ In order to improve the $\mathrm{CO}_{2}$ adsorption capacity and selectivity (over nitrogen) of materials, PSM methods were also used to modify relevant MOFs, e.g., functionalization of $\mathrm{Cu}$-BTTri with ethylenediamine ${ }^{41}$ and of $\mathrm{Mg}_{2}(\mathrm{dobdc})$ with tetraethylenepentamine. ${ }^{42}$

In this regard, PSM might be an effective method to solve the major drawback of poor hydrothermal stability for MOFs with OMSs. In this contribution, we report a simple PSM method to prepare molecular glycine-grafted CuBTC MOFs aimed at (i) hindering water adsorption on OMSs (to improve hydrothermal stability) and (ii) enhancing the interaction with $\mathrm{CO}_{2}$ (to increase the selectivity to $\mathrm{CO}_{2}$ ). Rationales behind the choice of using glycine molecules as the dopant are (i) the dimension of the glycine molecules (i.e., length $\approx 4.4 \AA$ and width $\approx 3.2 \AA$ ) allowing the diffusion of glycine molecules into pores of CuBTC MOF and (ii) the amine and carboxyl group in glycine allowing the interaction with both OMSs, i.e., unsaturated copper centers) and $\mathrm{CO}_{2}$ molecules.

\section{EXPERIMENTAL SECTION}

Materials. Copper(II) nitrate trihydrate $\left[\mathrm{Cu}\left(\mathrm{NO}_{3}\right)_{2} \cdot 3 \mathrm{H}_{2} \mathrm{O}\right.$, 99\%], benzene-1,3,5 tricarboxylic acid (BTC, 95\%), and amino acetic acid (glycine, $\geq 99 \%$ ) were purchased from Sigma-Aldrich, and ethanol (absolute) was obtained from Fisher. Materials were used as received without further purification.

Synthesis. CUBTC MOF Synthesis. CuBTC MOF was synthesized using an improved hydrothermal method at 100 ${ }^{\circ} \mathrm{C} .{ }^{10}$

Gly-CUBTC MOF Synthesis. Glycine grafted CuBTC MOFs (denoted as Gly-CuBTC) were prepared using a simple PSM method. Glycine crystals were fully grinded and dissolved in ethanol at $50{ }^{\circ} \mathrm{C}$ to give molecular glycine in solutions. The amount of glycine molecules was determined by the relevant percentage by weight (wt \%, glycine: $\mathrm{Cu}$ in $\mathrm{CuBTC}$ ). CuBTC MOF was then added to the molecular glycine solution in ethanol. The mixture was left to stir for $24 \mathrm{~h}$ at $50{ }^{\circ} \mathrm{C}$ and then washed with $60 \mathrm{~mL}$ of ethanol and activated at $120{ }^{\circ} \mathrm{C}$ under vacuum for $16 \mathrm{~h}$. Three Gly-CuBTC samples were synthesized with 10,20 , and 28 wt \% loading of molecular glycine in the parent CuBTC MOF (weight percent of glycine in Gly-CuBTC MOF). It was assumed that one molecule of glycine can occupy one copper atom. OMSs in $28 \mathrm{wt} \%$ Gly-CuBTC were believed to be fully saturated by glycine molecules (the theoretical mass fraction of copper in the CuBTC MOF is $31.5 \%{ }^{43}$ ). Accordingly, Gly-CuBTC MOFs containing 20 and 10 wt \% of glycine correspond to materials with $71 \%$ and $36 \%$ of $\mathrm{Cu}$ OMSs covered by glycine molecules. Details of the calculation are available in the Supporting Information.

Characterization. Powder X-ray diffraction (PXRD) was carried out using a Rigaku Miniflex diffractometer $(\mathrm{Cu} \mathrm{K} \alpha$ radiation, $30 \mathrm{kV}, 15 \mathrm{~mA}, \lambda=1.5406 \AA$ ) with a step scan mode $\left(0.03^{\circ}\right.$ per step) and a range of $5^{\circ}<2 \theta<46^{\circ}$. Scanning electron microscopy (SEM) analysis was performed using FEI Quanta 200 ESEM equipment with a high voltage mode of $20 \mathrm{kV}$. All samples were coated with platinum prior to the SEM imaging in order to create a conductive layer on the surface of materials to inhibit their charging. The platinum coating was performed using the Cressington sputter coater under vacuum conditions of 0.01 $\operatorname{mbar}(\mathrm{G})$. The thermogravimetric analysis (TGA) was carried out with a TA Q5000 (V3.15 Build 263) thermogravimetric analyzer. The temperature range was $0-450{ }^{\circ} \mathrm{C}$ with a heating rate of $5{ }^{\circ} \mathrm{C} \mathrm{min}^{-1}$ under a nitrogen atmosphere $(25 \mathrm{~mL} / \mathrm{min})$.

FT-IR analysis was carried out using solid FT-IR Avatar 360 ESP spectrometer instrument in the range of $650-4000 \mathrm{~cm}^{-1}$ with ATR accessory that contains a germanium crystal conjointly with Nicolet's OMNIC software. Raman analyses were carried out using JY Horiba LabRam 300 Confocal Raman microscope. A $632.82 \mathrm{~nm}$ HeNe laser was used as the excitation source. The acquisition time of $100 \mathrm{~s}$ and 3 accumulations were used for each analysis. The collection optics was set at $100 \times$ with $1 \%$ laser power (full laser power $=10 \mathrm{~mW}$ ).

Nitrogen adsorption isotherms of materials at $-196{ }^{\circ} \mathrm{C}$ were obtained using the Micrometrics accelerated surface area and porosimetry (ASAP) 2020 analyzer. Prior to the measurement of adsorption isotherms, samples were prepared at $200{ }^{\circ} \mathrm{C}$ under vacuum for $8 \mathrm{~h}$. Equilibration time of $45 \mathrm{~s}$ was specified for each data point of isotherms during the analysis. The BrunauerEmmett-Teller (BET) method was applied to determine specific surface areas of materials.

Gas Adsorption Measurements. $\mathrm{CO}_{2}$ and $\mathrm{N}_{2}$ Adsorption. Single-component $\mathrm{CO}_{2}$ or $\mathrm{N}_{2}$ adsorption on materials was carried out the Intelligent gravimetric analyzer (Hiden Analytical, 


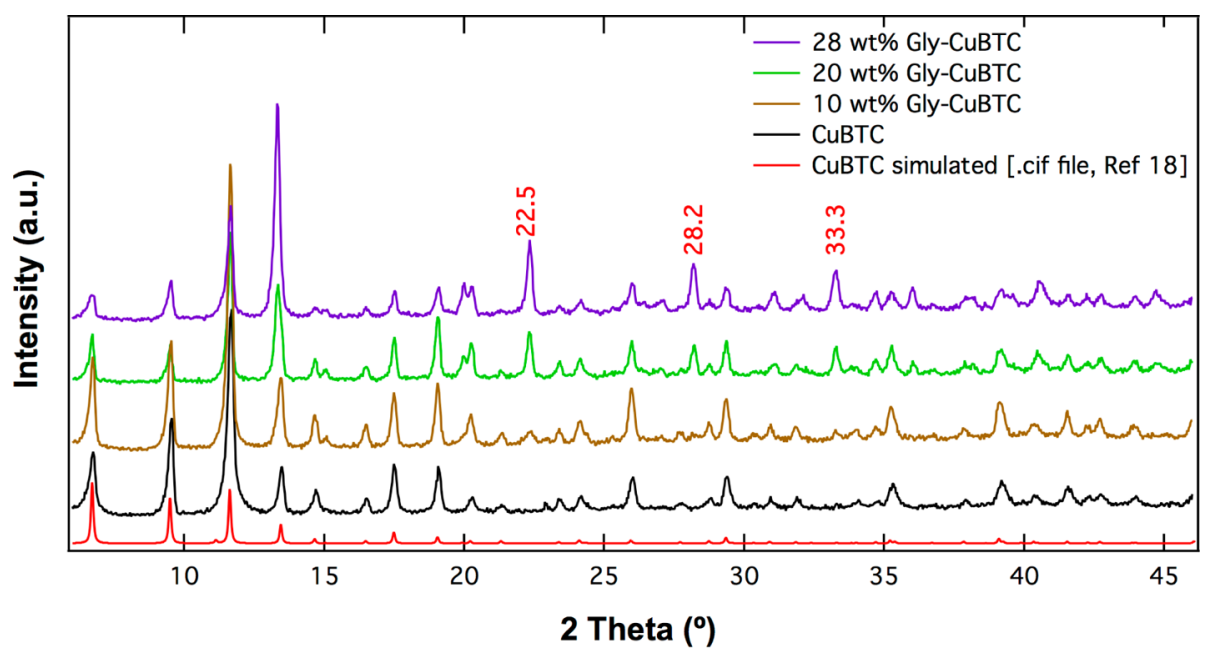

Figure 2. PXRD patterns of CuBTC MOF and Gly-CuBTC MOFs (with 10, 20, and 28 wt \% loading of glycine).

IGA-001). Samples were thermally degassed at $100{ }^{\circ} \mathrm{C}$ for $3 \mathrm{~h}$ and then at $200{ }^{\circ} \mathrm{C}$ (heating rate $=2{ }^{\circ} \mathrm{C} / \mathrm{min}$ ) for $8 \mathrm{~h}$ under vacuum. Buoyancy effects were assessed to determine the density of materials with helium adsorption prior to gas adsorption measurements. Single-component adsorption isotherms were collected at 25 and $50{ }^{\circ} \mathrm{C}$, respectively. At each pressure point, the system was left to equilibrate for maximum $2 \mathrm{~h}$.

Water Vapor Adsorption. Water vapor adsorption isotherms were measured gravimetrically using a dynamic vapor adsorption analyzer (Surface Measurements Systems, DVS 1). The analyzer was housed inside an environmental chamber at a constant temperature to ensure a stable baseline and the accurate delivery of required values of the relative humidity $(\mathrm{RH})$. A required value of RH was achieved by mixing dry nitrogen and saturated water vapor in appropriate proportions using mass flow controllers. Prior to the sample loading, dry nitrogen at $2 \mathrm{bar}(\mathrm{G})$ pressure was used to purge the head of the balance (Cahn D200) in order to prevent the vapor condensation in the balance's head and ensure an accurate measurement. All samples were dried at $0 \%$ relative humidity for $6 \mathrm{~h}$ before the measurement of adsorption/ desorption isotherms at various vapor partial pressures. Water vapor adsorption isotherms of materials were measured at temperatures of 25 and $50{ }^{\circ} \mathrm{C}$ with $\mathrm{RH}$ values ranging from 0 to $90 \%$.

\section{RESULTS AND DISCUSSION}

Characterization of Gly-CuBTC MOF. Gly-CuBTC MOFs were prepared using a simple PSM method developed in this study. The as-made Gly-CuBTC MOF (Figure 1a) exhibits a sky blue color, while the activated Gly-CuBTC MOF renders a royal blue color differencing them from the corresponding CuBTC samples. ${ }^{10}$ By comparing PXRD patterns of Gly-CuBTs with that of CuBTC MOFs (Figure 2), characteristic peaks (i.e., at $2 \theta \approx$ $6.5^{\circ}, 9.5^{\circ}, 11.5^{\circ}$ and $13.4^{\circ}$ ) of CuBTC $\mathrm{MOF}^{10}$ were clearly identifiable in the PXRD patterns of Glu-CuBTC MOFs suggesting the preservation of the parent framework structure of CuBTC. Additional diffraction peaks in Gly-CuBTC samples, as shown by $2 \theta$ peak positions of $22.5^{\circ}, 28.2^{\circ}$ and $33.3^{\circ}$, can be attributed to the addition of molecular glycine. The intensity of these peaks was found to vary in relation to the doped amount of molecular glycine. SEM analyses showed that the size and morphology of the Gly-CuBTC crystals were similar to that of CuBTC MOF (Figure 1b).
Thermal behaviors of CuBTC MOF, Gly-CuBTC MOFs, and pure glycine were evaluated using TGA under an inert atmosphere, as shown in Figure 3. All MOFs demonstrated

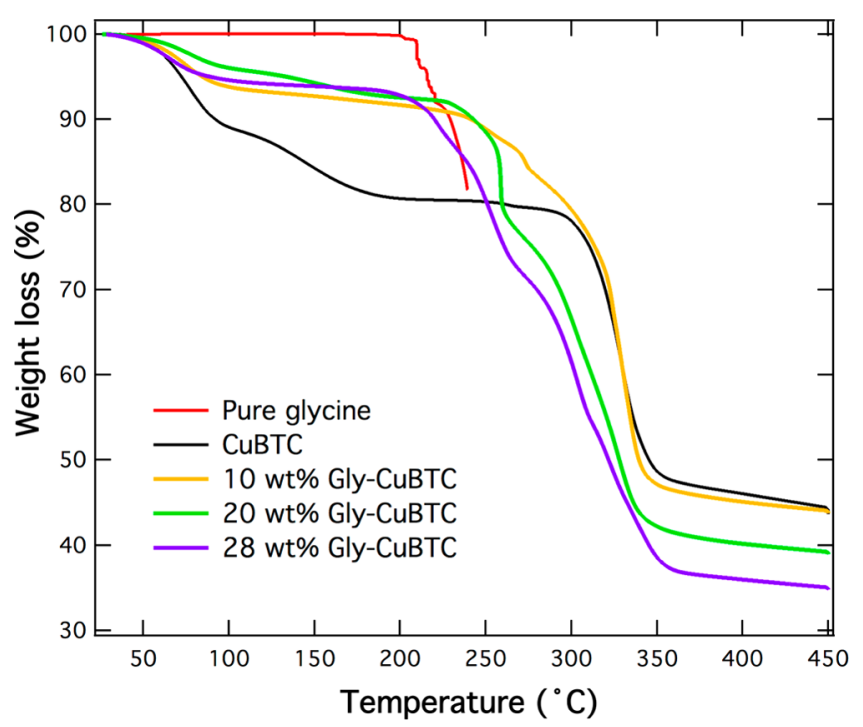

Figure 3. TGA curves of CuBTC MOF, Gly-CuBTC MOFs, and glycine.

two steps of weight loss including their final decomposition in $\mathrm{TG}$ analysis. The first step of weight loss $\left(50-100^{\circ} \mathrm{C}\right.$, ca. $\left.8 \%\right)$ for Gly-CuBTC MOFs can be attributed to the loss of water molecules, which was much lower than that of CuBTC MOF (ca. 20\%). This result indicates that Gly-CuBTC MOFs obtained by the glycine grafting are more hydrophobic than the parent CuBTC MOF.

Plateaus measured for Gly-CuBTC samples indicated that glycine molecules cannot desorb from the parent $\mathrm{CuBTC}$ under heating (measured melting point of glycine is ca. $205{ }^{\circ} \mathrm{C}$ ). However, the loaded amount of glycine (with a measured melting point of $200{ }^{\circ} \mathrm{C}$ ) was found to have a direct impact on the decomposition temperature of Gly-CuBTC MOFs, resulting in a decrease in the thermal stability of materials with an increase in the amount of glycine. Differential thermogravimetric analysis of TG curves revealed that decomposition temperatures are respectively 270,258 , and $220{ }^{\circ} \mathrm{C}$ for 10,20 , and $28 \mathrm{wt} \%$ Gly- 


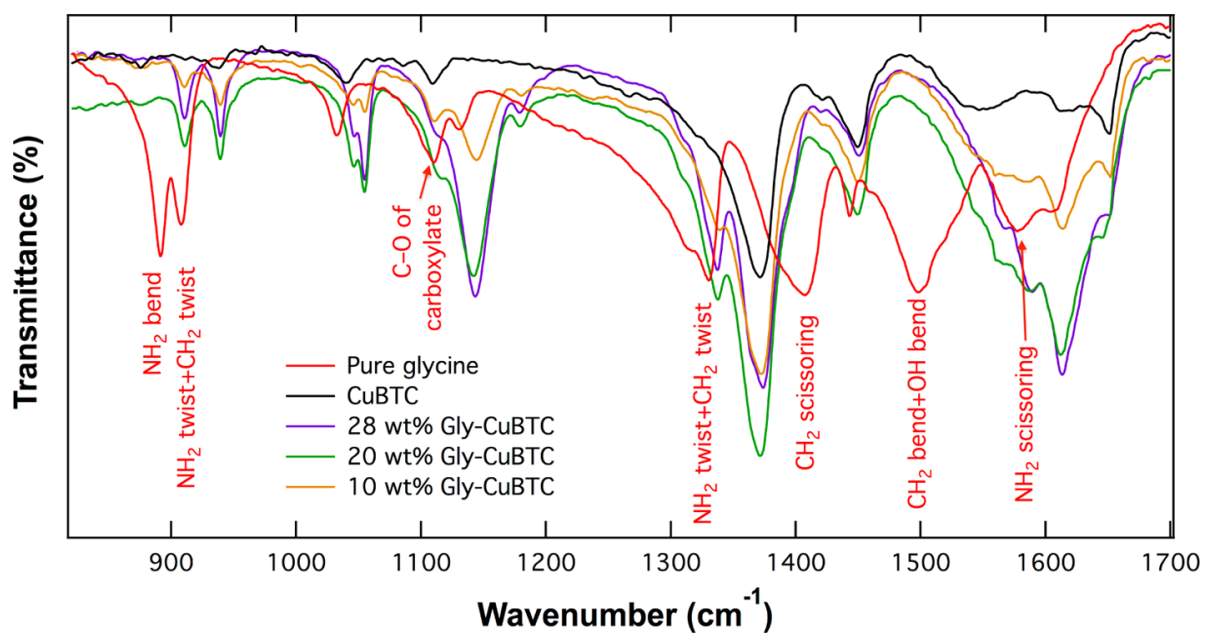

Figure 4. FT-IR spectra of CuBTC MOF, glycine, and Gly-CuBTC MOFs.

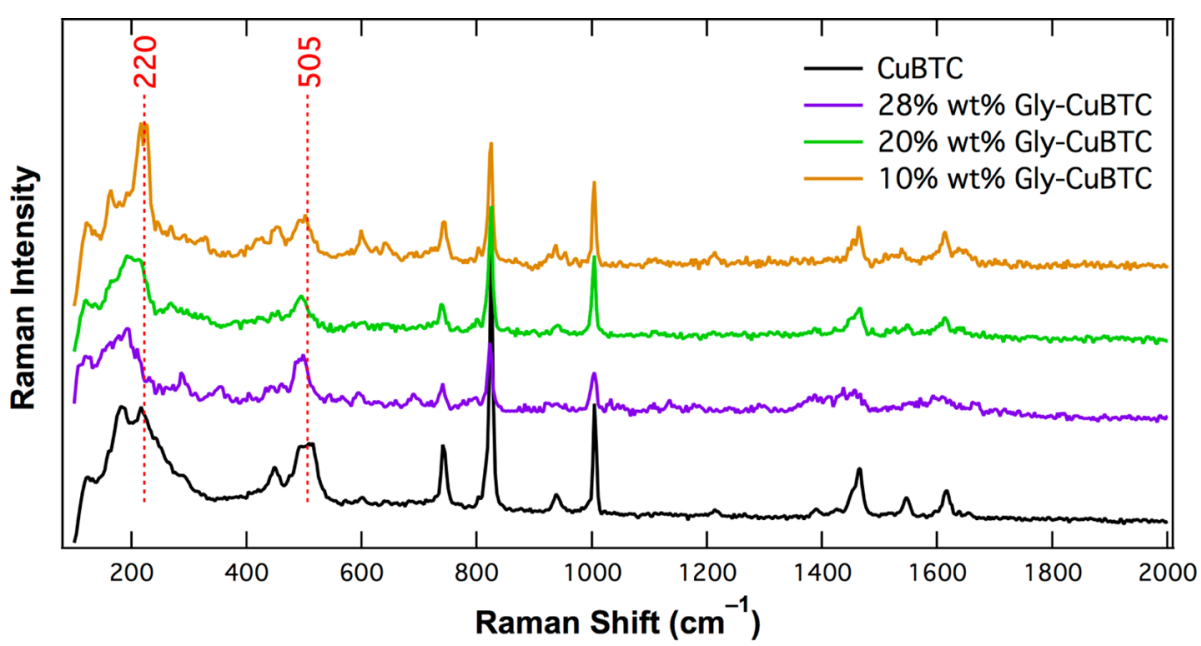

Figure 5. Raman spectra of CuBTC MOF and Gly-CuBTC MOFs.

CuBTC MOFs, whereas the final decomposition of CuBTC MOF happened at $310{ }^{\circ} \mathrm{C}$. TGA suggested that $200{ }^{\circ} \mathrm{C}$ is the upper boundary for practical applications of Gly-CuBTC MOFs making them still suitable for gas adsorption.

The structural vibration of materials after the glycine grafting was investigated by using FT-IR (Figure 4) and Raman spectroscopies (Figure 5). FT-IR analysis (Figure 4) showed that Gly-CuBTC samples preserve vibrational properties of both pure CuBTC and glycine. Characteristic bands of CuBTC MOF at 1645,1445 , and $1375 \mathrm{~cm}^{-1}$ are still evident in Gly-CuBTC samples ${ }^{44}$ confirming the result from PXRD analysis. Such results suggest that the coordination in $\mathrm{Cu}_{2} \mathrm{C}_{4} \mathrm{O}_{8}$ cages of the CuBTC framework is intact after the PSM modification using glycine. By comparing FT-IR spectra of glycine with that of GlyCuBTC MOFs, no band shift is noticed for the $\mathrm{CO}$ stretch at ca. $1110 \mathrm{~cm}^{-1}$ in the carboxylic group of glycine molecules. However, characteristic bands corresponding to the $\mathrm{NH}_{2}$ moiety were found shifted to higher wavelengths in spectra of the GlyCuBTC samples. Such shifts can be ascribed to the interaction of glycine molecules to copper centers of the parent $\mathrm{CuBTC}$ MOF through the nitrogen atom in glycine.

The low-frequencies region $\left(900-170 \mathrm{~cm}^{-1}\right)$ was further investigated by using Raman spectroscopy (Figure 5). It has been reported that vibrational modes directly related to $\mathrm{Cu}$ (II) species in CuBTC MOF appear in wavelengths $<600 \mathrm{~cm}^{-1}$. 45,46
In Figure 5, the characteristic doublet at $502 \mathrm{~cm}^{-1}$ (strong) and at $448 \mathrm{~cm}^{-1}$ (weak) corresponding to $\mathrm{Cu}-\mathrm{O}$ vibrations ${ }^{45,46}$ can be clearly identified in Raman spectra of all samples. With an increase of glycine loading, the frequency of the weak band at 448 $\mathrm{cm}^{-1}$ declined, suggesting the weakening of this bond. This is likely to originate from the glycine- $\mathrm{Cu}$ interaction affecting $\mathrm{Cu}-$ $\mathrm{O}$ vibrations in CuBTC. Another band at $505 \mathrm{~cm}^{-1}$ associated with $\mathrm{Cu}-\mathrm{O}$ stretching in the parent $\mathrm{CuBTC}$ was also found to shift slightly to a lower wavelength in Gly-CuBTC spectra.

According to Dhumal et al., ${ }^{45}$ the $\mathrm{Cu}-\mathrm{Cu}$ stretching band appears at $228 \mathrm{~cm}^{-1}$ for the fully activated CuBTC MOF, and the hydration of OMSs in CuBTC can result in a frequency shift to a lower wavelength. The interaction between adsorbed water molecules and $\mathrm{Cu}$ centers in the hydrated CuBTC MOF causes the elongation of $\mathrm{Cu}-\mathrm{Cu}$ bonds reducing the energy that is required for $\mathrm{Cu}-\mathrm{Cu}$ bonds to stretch. CuBTC MOF is extremely hydrophilic and is able to attract the moisture immediately upon exposure to the atmosphere. In this study, the band of $\mathrm{Cu}-\mathrm{Cu}$ stretching was observed at $220 \mathrm{~cm}^{-1}$ for the partially hydrated CuBTC (solid line in Figure 5). In Gly-CuBTC MOFs, glycine molecules are expected to interact with $\mathrm{Cu}$ centers in a manner similar to water molecules, i.e., glycine molecules adsorbed on $\mathrm{Cu}$ centers, influencing the $\mathrm{Cu}-\mathrm{Cu}$ bond stretching. Therefore, the shift of $\mathrm{Cu}-\mathrm{Cu}$ bonds to lower wavelengths in Raman spectra of Gly-CuBTC MOFs can be explained. 
Nitrogen adsorption at $-196^{\circ} \mathrm{C}$ was used to assess the effect of the PSM modification (using glycine) on the BET surface area of materials. As shown in Figure 6, grafting the CuBTC MOF

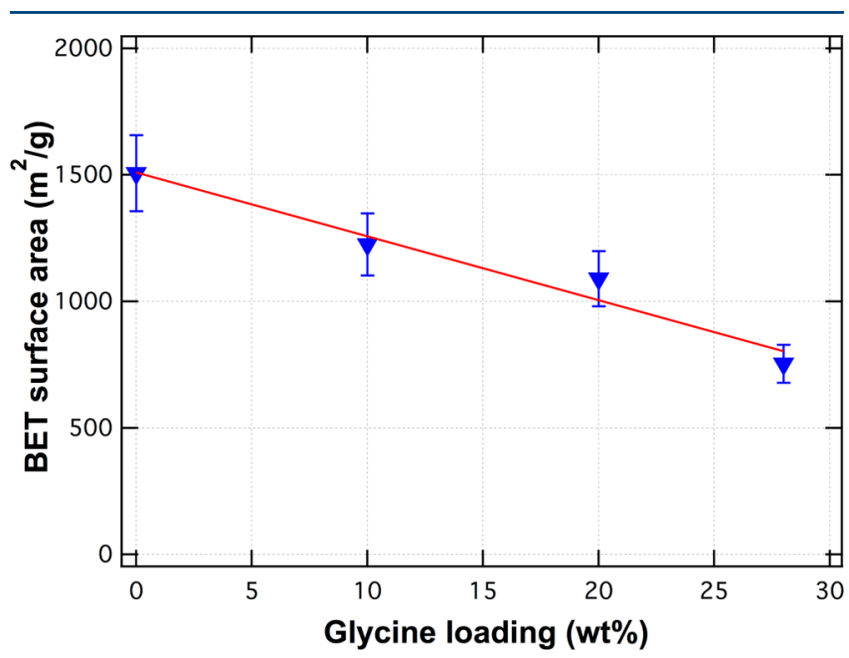

Figure 6. BET surface areas of CuBTC MOF and Gly-CuBTC MOFs.

using glycine molecules resulted in the reduction of the BET surface area of Gly-CuBTC MOFs. In general, the BET surface area of Gly-CuBTC MOFs decreased in a linear fashion with an increase in the loading amount of molecular glycine. Such phenomenon can be expected since alien glycine molecules can diffuse into the porous structure of the parent $\mathrm{CuBTC}$ MOF and attach to OMSs reducing the available pore volume and surface area of Gly-CuBTC MOFs (surface density of a OMS $\approx 33 \AA$ )..$^{47}$

$\mathrm{CO}_{2}$ and $\mathrm{N}_{2}$ Adsorption on Gly-CuBTC MOFs. GlyCuBTC MOFs were evaluated using pure $\mathrm{CO}_{2}$ and $\mathrm{N}_{2}$ adsorption experiments, and isotherms of the materials (at 25 and $50{ }^{\circ} \mathrm{C}$ ) are shown in Figure 7. For both probing gases, the

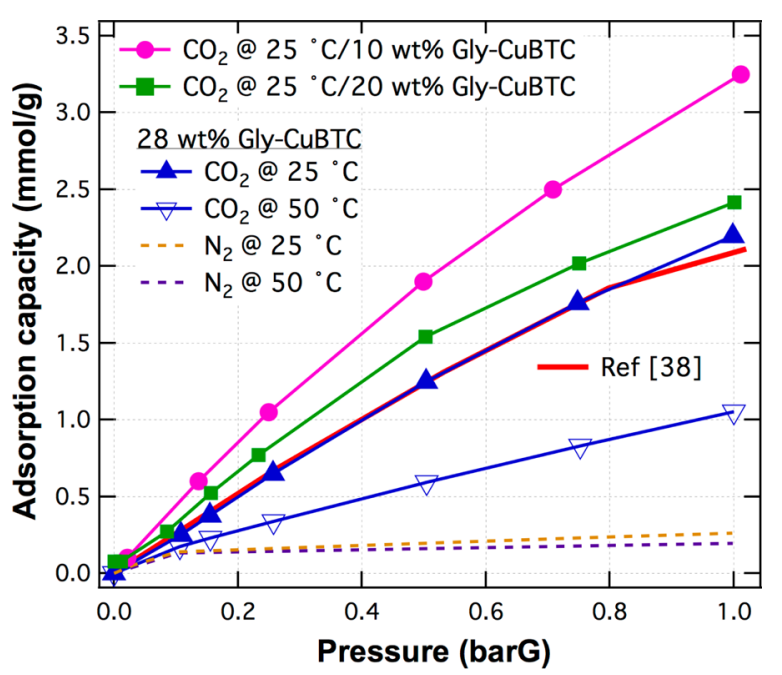

Figure 7. Pure $\mathrm{CO}_{2}$ and $\mathrm{N}_{2}$ adsorption isotherms on Gly-CuBTC MOFs.

adsorption temperature showed an adverse effect on the adsorption capacity of Gly-CuBTC MOF, e.g., $\mathrm{CO}_{2}$ uptake of 28 wt \% Gly-CuBTC decreased by ca. $45 \%$ with an increase in temperature from 25 to $50{ }^{\circ} \mathrm{C}$ at $1 \mathrm{bar}(\mathrm{G})$, indicating the physisorption of probing molecules on Gly-CuBTC. The $\mathrm{CO}_{2}$ adsorption capacity of Gly-CuBTC MOFs at $1 \mathrm{bar}(\mathrm{G})$ was found to decrease with an increase in the amount of glycine, as shown in Figure 7 and Table 1 . This can be attributed to the occupation of

Table 1. Measured and Calculated Adsorption Capacity of Pure $\mathrm{CO}_{2}$ on CuBTC and Gly-CuBTC MOFs at 1 bar(G)

\begin{tabular}{|c|c|c|c|c|}
\hline & $\begin{array}{c}\text { BET } \\
\text { area } \\
{\left[\mathrm{m}^{2} / \mathrm{g}\right]}\end{array}$ & $\begin{array}{c}\text { temperature } \\
{\left[{ }^{\circ} \mathrm{C}\right]}\end{array}$ & $\begin{array}{c}\mathrm{CO}_{2} \text { adsorption } \\
\text { capacity } \\
{[\mathrm{mmol} / \mathrm{g}]}\end{array}$ & $\begin{array}{c}\mathrm{CO}_{2} \text { adsorption } \\
\text { capacity } \\
{[\text { molecule/UC }]}\end{array}$ \\
\hline \multirow[t]{2}{*}{ CuBTC } & \multirow[t]{2}{*}{1507} & 25 & 4.45 & 43.1 \\
\hline & & 50 & 2.45 & 23.7 \\
\hline \multirow{2}{*}{$\begin{array}{l}10 \text { wt } \% \\
\text { Gly- } \\
\text { CuBTC }\end{array}$} & \multirow[t]{2}{*}{1225} & 25 & 3.25 & 35.6 \\
\hline & & 50 & 1.06 & 11.6 \\
\hline \multirow{2}{*}{$\begin{array}{l}20 \text { wt } \% \\
\text { Gly- } \\
\text { CuBTC }\end{array}$} & \multirow[t]{2}{*}{1090} & 25 & 2.42 & 29.6 \\
\hline & & 50 & 0.967 & 11.8 \\
\hline \multirow{2}{*}{$\begin{array}{l}28 \text { wt } \% \\
\text { Gly- } \\
\text { CuBTC }\end{array}$} & \multirow[t]{2}{*}{753} & 25 & 2.20 & 29.2 \\
\hline & & 50 & 0.450 & 5.98 \\
\hline
\end{tabular}

the available pore volume in the framework of MOFs by glycine molecules leading to a decrease in the packing capacity of GlyCuBTC MOFs. $\mathrm{CO}_{2}$ and $\mathrm{N}_{2}$ adsorption on Gly-CuBTC MOFs is reversible, as shown in Figure $S 1$.

At $25{ }^{\circ} \mathrm{C}$ and 1 bar( $(\mathrm{G})$, the measured $\mathrm{CO}_{2}$ adsorption capacity of $28 \mathrm{wt} \%$ Gly-CuBTC was about $2.2 \mathrm{mmol} / \mathrm{g}$ and comparable to that of a polydimethysiloxane (PDMS)-coated CuBTC $\mathrm{MOF}^{38}$ (red solid line in Figure 7). By coating CuBTC MOF using the hydrophobic PDMS, ${ }^{38}$ all available OMSs in the parent MOF were expected to be protected by PDMS. For 28 wt \% GlyCuBTC, a similar scenario was anticipated with all OMSs in $\mathrm{CuBTC}$ occupied by glycine molecules. Therefore, a comparable saturating $\mathrm{CO}_{2}$ adsorption capacity was predicted for both materials. However, the developed PSM method for preparing Gly-CuBTC MOFs in this study was much simpler than the one for preparing the PDMS-coated CuBTC, in which the vapor deposition method at $235{ }^{\circ} \mathrm{C}$ is needed. ${ }^{38}$

The measured $\mathrm{CO}_{2}$ adsorption capacity and calculated $\mathrm{CO}_{2}$ adsorption capacity (as the number of $\mathrm{CO}_{2}$ molecules per unit cell (UC) of MOFs) are summarized in Table 1. By comparing the values of the calculated $\mathrm{CO}_{2}$ adsorption capacity, one can develop the intuitive understanding of how the attachment of glycine molecules on OMSs in CuBTC can reduce the packing capacity of resulting Gly-CuBTC MOFs. For example, the number of packed $\mathrm{CO}_{2}$ molecules in one $\mathrm{UC}$ at $25^{\circ} \mathrm{C}$ and 1 $\operatorname{bar}(\mathrm{G})$ is reduced by ca. $32 \%$ by saturating all OMSs in CuBTC.

Considering the practical application of MOFs for $\mathrm{CO}_{2}$ capture from flue gases, where nitrogen is the largest constituent (70-75 vol \%), the $\mathrm{CO}_{2}: \mathrm{N}_{2}$ selectivity of materials was important for efficient removal of $\mathrm{CO}_{2}$. On the basis of the single-component adsorption data measured in this study, the Ideal Adsorbed Solution Theory (IAST) ${ }^{48,49}$ was employed to estimate the selectivity of developed materials in multicomponent adsorption equilibria. By comparing with the parent $\mathrm{CuBTC}$, the $\mathrm{CO}_{2}: \mathrm{N}_{2}$ selectivity (in a system with 15.6 vol \% $\mathrm{CO}_{2}$ ) was improved for the doped CuBTC MOF, i.e., $33 \%$ for 28 wt \% Gly-CuBTC versus $26 \%$ for CuBTC at $25{ }^{\circ} \mathrm{C}$ and $19 \%$ for 28 wt \% Gly-CuBTC versus $16 \%$ for CuBTC at $50{ }^{\circ} \mathrm{C}$.

The improved $\mathrm{CO}_{2}: \mathrm{N}_{2}$ selectivity of Gly-CuBTC MOF can be mainly attributed to the enhanced interaction of Gly-CuBTC with $\mathrm{CO}_{2}$ molecules by the addition of polar glycine molecules ${ }^{50}$ to the parent framework (electric quadruple moment: $\mathrm{CO}_{2}=$ 13.4 $\mathrm{C} \mathrm{m}^{2}$ versus $\left.\mathrm{N}_{2}=4.72 \mathrm{C} \mathrm{m}^{2}\right)$. ${ }^{51}$ Furthermore, the reduced pore volume of Gly-CuBTC MOF also has the beneficial effect 

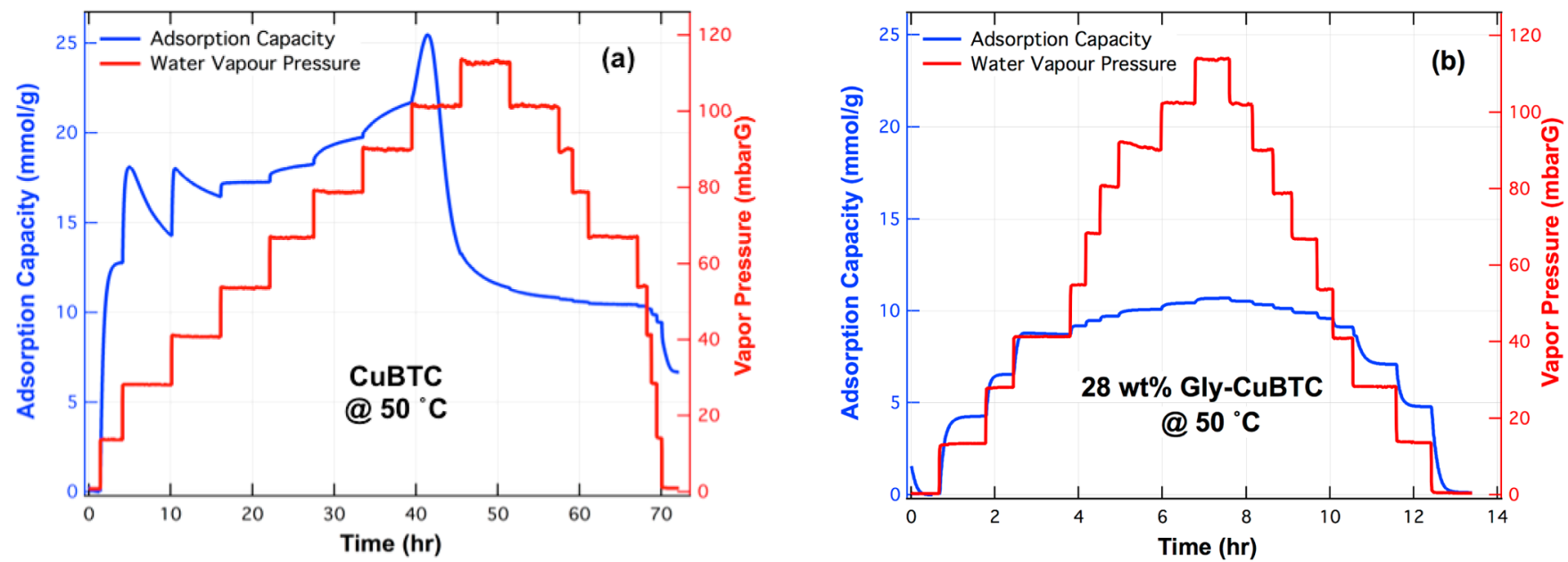

Figure 8. (a) Temporal water vapor adsorption on $28 \mathrm{wt} \%$ Gly-CuBTC at $50{ }^{\circ} \mathrm{C}$. (b) Temporal water vapor adsorption on $\mathrm{CuBTC}$ at $50{ }^{\circ} \mathrm{C}$.
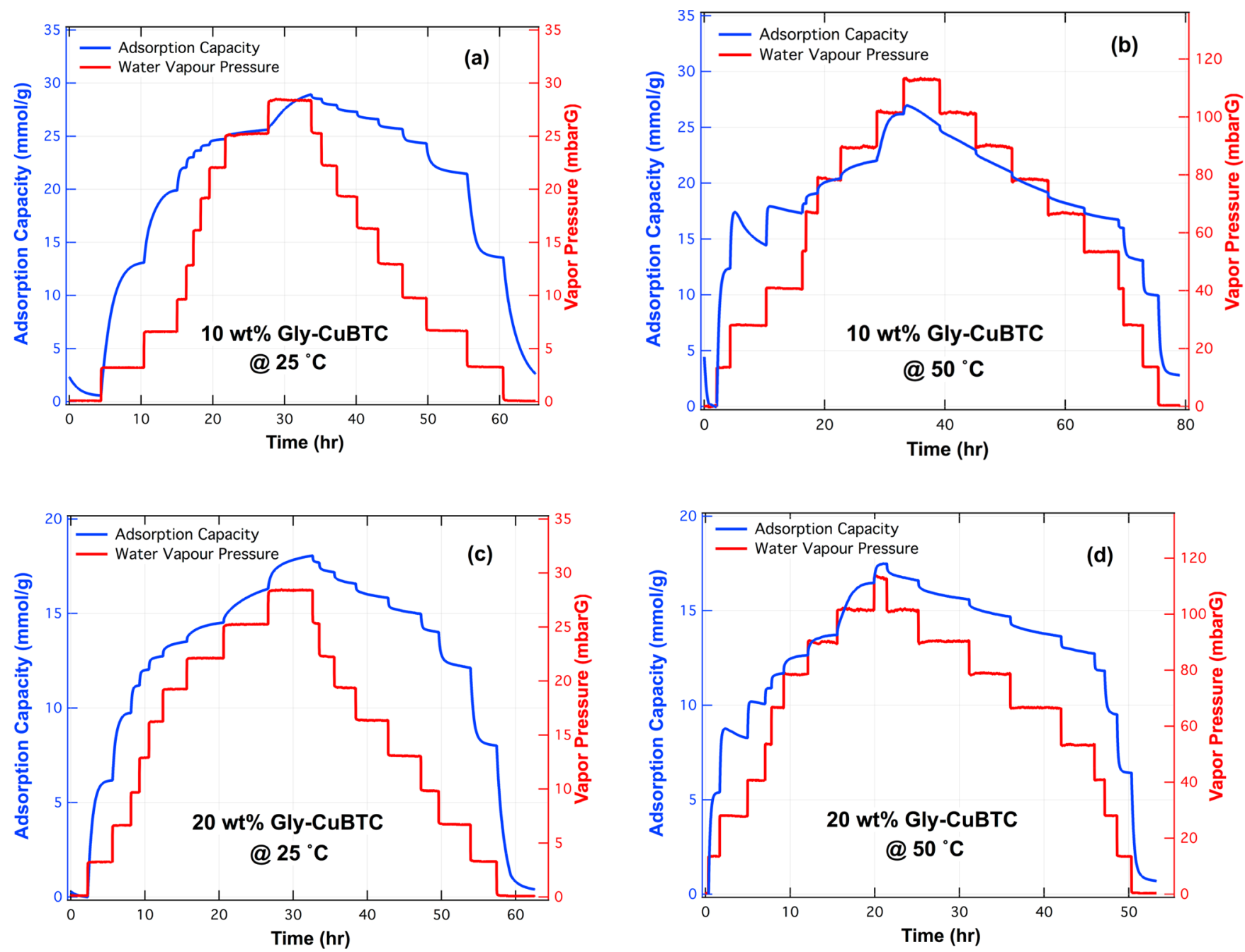

Figure 9. (a, b) Temporal water vapor adsorption on $10 \mathrm{wt} \%$ Gly-CuBTC. (c, d) Temporal water vapor adsorption on 20 wt \% Gly-CuBTC.

on the selectivity to $\mathrm{CO}_{2}$ due to the intensified adsorbateadsorbent interactions in constricted pores. ${ }^{52}$

Improved Hydrothermal Stability of Gly-CuBTC MOFs.

The hydrothermal stability of Gly-CuBTC MOFs was evaluated using dynamic water vapor adsorption experiments (experiments are reproducible with ca. $15 \%$ standard deviation on the measured adsorbed amount of water vapor). Figure 8 shows the comparison of the dynamic of water vapor adsorption on the parent CuBTC and 28 wt \% Gly-CuBTC at $50{ }^{\circ} \mathrm{C}$ (simulating the flue gas emitting conditions; isotherms are shown in Figure S2). It was measured that the modified CuBTC (28 wt \% GlyCuBTC) became hydrophobic after the PSM treatment of 
CuBTC using glycine, evidenced by the reduced amount of water uptake (by ca. 50\%, 28 wt \% Gly-CuBTC vs CuBTC).

Moreover, the hydrothermal stability of Gly-CuBTC was also found to enhance significantly in comparison with the parent CuBTC. For dynamic water vapor adsorption on CuBTC (Figure 8a), anomalous spikes (showing the sudden loss of adsorbed water molecules) were measured at partial water vapor pressures of ca. 24.7 and $37 \mathrm{mbar}(\mathrm{G})$ suggesting the partial decomposition of CuBTC framework during the water vapor adsorption process. At a partial water vapor pressure of 86 $\operatorname{mbar}(\mathrm{G})$, a sudden drop of the adsorption capacity of CuBTC represented the complete collapse of CuBTC framework caused by the aggregation of water molecules in the parent framework destroying the $\mathrm{Cu}-\mathrm{BTC}$ coordination. ${ }^{21,25}$ The loss of porous structure due to the water-induced decomposition of CuBTC also resulted in a shorter time of desorption (comparing with the adsorption step), evidenced by asymmetric pressure stages in Figure 8 a. In contrast, temporal data of water vapor adsorption on 28 wt \% Gly-CuBTC demonstrated a stable material for one cycle of water vapor adsorption and desorption. Furthermore, a much shorter equilibrium time was required for Gly-CuBTC than CuBTC in experiments of dynamic water vapor adsorption showing the high moisture/water resistance of Gly-CuBTC MOFs developed by the PSM treatment.

Ten wt $\%$ and 20 wt \% Gly-CuBTC MOFs were also evaluated using dynamic water vapor adsorption experiments at 25 and 50 ${ }^{\circ} \mathrm{C}$, respectively, and relevant results are presented in Figure 9. Ten wt $\%$ and 20 wt \% Gly-CuBTC samples demonstrated good moisture stability under humid streams at $25{ }^{\circ} \mathrm{C}$, as shown in Figure $9 \mathrm{a}$ and $\mathrm{c}$, showing no signs of the partial decomposition. Gly-CuBTC MOFs almost returned to their original masses $( \pm 2.5 \%$ margin $)$ after dynamic water vapor adsorption experiments under different conditions, suggesting almost complete water desorption from materials. PXRD analyses of spent GlyCuBTC MOFs (Figure S3) also confirmed the stability of developed materials. However, spikes in the adsorption capacity of materials were detected for both samples at $50{ }^{\circ} \mathrm{C}$ (Figure $9 \mathrm{~b}$ and $\mathrm{d}$ ), suggesting the partial degradation of framework structures under humid conditions.

OMSs in 10 and 20 wt \% Gly-CuBTC MOFs were only partially covered by $36 \%$ and $71 \%$, respectively, with glycine molecules. Therefore, unprotected OMSs in these materials are subject to interact with water molecules under humid conditions resulting in the displacement of BTC linkers from Cu centers ${ }^{21,25}$ and hence the partial degradation of materials. In contrast to CuBTC MOF (Figure 8b), complete structural breakdown was not observed in experiments for 10 and $20 \mathrm{wt} \%$ Gly-CuBTC samples because protected copper centers (by adsorbed glycine molecules) remained intact under humid streams, sustaining the structural integrity of Gly-CuBTC. In summary, the partial degradation of glycine modified CuBTC frameworks at $50{ }^{\circ} \mathrm{C}$ was inevitable if OMSs in the parent CuBTC were not fully saturated by the dopant. Therefore, results obtained from the dynamic water vapor adsorption on Gly-CuBTC MOFs suggest that all OMSs in CuBTC need to be protected by the molecular dopant in order to ensure the hydrothermal stability of materials in the presence of water or humidity at room or elevated temperatures.

Furthermore, it is also worth noting that for Gly-CuBTC MOFs the effect of operating temperature has little effect on the saturated water vapor adsorption capacity of materials. For $\mathrm{CuBTC}$, the overall water vapor uptake was reduced by ca. $50 \%$ with an increase in temperature from 25 to $50{ }^{\circ} \mathrm{C}$, while for Gly-
CuBTC M OFs, only a ca. $20 \%$ drop in the overall water vapor uptake was measured.

\section{CONCLUSIONS}

This paper reports a simple and economical post-synthetic modification (PSM) method for the synthesis of glycine-doped CuBTC MOF, without using complex synthetic procedures and apparatus. The resulting glycine-doped CuBTC MOF, i.e., GlyCuBTC MOF, was fully characterized by using PXRD, SEM, FTIR, Raman, and $\mathrm{N}_{2}$ adsorption. Glycine molecules were found to be able to saturate open metal sites (OMSs) in the parent CuBTC framework leading to (i) diminished affinity to water molecules and (ii) enhanced interaction with $\mathrm{CO}_{2}$ molecules.

The Gly-CuBTC MOF was assessed using single component (i.e., $\mathrm{CO}_{2}, \mathrm{~N}_{2}$, and water vapor) adsorption experiments. In comparison with the parent CuBTC MOF, the developed $28 \mathrm{wt}$ $\%$ Gly-CuBTC MOF showed a reduced water vapor adsorption capacity (by ca. $57 \%$ at $50{ }^{\circ} \mathrm{C}$ and $90 \% \mathrm{RH}$ ) and an improved $\mathrm{CO}_{2}: \mathrm{N}_{2}$ selectivity (by ca. $15 \%$ at $50{ }^{\circ} \mathrm{C}$, with 15.6 vol \% $\mathrm{CO}_{2}$ composition). Furthermore, compared with $\mathrm{CuBTC}$, the $28 \mathrm{wt}$ $\%$ Gly-CuBTC MOF also showed better stability under various humid conditions (up to $90 \% \mathrm{RH}$ at $50{ }^{\circ} \mathrm{C}$ ) demonstrating its suitability for practical applications.

Our results present the development of a facile PSM method using an economical dopant (glycine), which could represent a cost-effective approach for preparing hydrothermal stable materials based on the available bulk MOFs for practical $\mathrm{CO}_{2}$ capture from humid streams. Though only one parent MOF of the CuBTC framework was investigated in this study, the method demonstrated here can be applied more generically to other MOFs with OMSs extending application fields of these materials, e.g., gas sorption and catalysis in the presence of water or humidity.

\section{ASSOCIATED CONTENT}

\section{S Supporting Information}

The Supporting Information is available free of charge on the ACS Publications website at DOI: 10.1021/acs.iecr.5b04217.

Determination of the weight percent of glycine in GlyCuBTC MOFs, isotherms of $\mathrm{CO}_{2}$ and $\mathrm{N}_{2}$ adsorption on Gly-CuBTC MOFs, isotherms of water vapor adsorption on materials, and PXRD analysis of used Gly-CuBTC MOFs from dynamic water vapor adsorption experiments. (PDF)

\section{AUTHOR INFORMATION}

\section{Corresponding Author}

*E-mail: xiaolei.fan@manchester.ac.uk. Tel.: +44 1613062690.

\section{Author Contributions}

H. Deng, J. Borges, and X. Liu contributed equally to the work. Notes

The authors declare no competing financial interest.

\section{ACKNOWLEDGMENTS}

We thank The University of Manchester (under the EPS Strategic Fund and the CEAS Pump Priming fund) for the financial support. N.A.J. thanks The Higher Committee for Education Development in Iraq for the postgraduate research scholarship. J.B. thanks Science without Borders (a Brazilian Government scholarship programme) for supporting her undergraduate sandwich courses at The University of Man- 
chester. We are also grateful to Dr. S. Holmes and Prof. R. Davey (CEAS, The University of Manchester) for $\mathrm{N}_{2}$ adsorption, PXRD, FT-IR. and Raman analyses of materials.

\section{REFERENCES}

(1) Zhou, H. C.; Long, J. R.; Yaghi, O. M. Introduction to MetalOrganic Frameworks. Chem. Rev. 2012, 112, 673-674.

(2) Sumida, K.; Rogow, D. L.; Mason, J. A.; McDonald, T. M.; Bloch, E. D.; Herm, Z. R.; Bae, T. H.; Long, J. R. Carbon Dioxide Capture in Metal-Organic Frameworks. Chem. Rev. 2012, 112, 724-781.

(3) Liu, J.; Thallapally, P. K.; McGrail, B. P.; Brown, D. R.; Liu, J. Progress in Adsorption-Based $\mathrm{CO}_{2}$ Capture by Metal-Organic Frameworks. Chem. Soc. Rev. 2012, 41, 2308-2322.

(4) Burtch, N. C.; Jasuja, H.; Walton, K. S. Water Stability and Adsorption in Metal-Organic Frameworks. Chem. Rev. 2014, 114 (20), 10575-10612.

(5) Fischer, M.; Gomes, J. R. B.; Jorge, M. Computational Approaches to Study Adsorption in MOFs with Unsaturated Metal Sites. Mol. Simul. 2014, 40, 537-556.

(6) Bordiga, S.; Regli, L.; Bonino, F.; Groppo, E.; Lamberti, C.; Xiao, B.; Wheatley, P. S.; Morris, R. E.; Zecchina, A. Adsorption Properties of HKUST-1 toward Hydrogen and Other Small Molecules Monitored by IR. Phys. Chem. Chem. Phys. 2007, 9, 2676-2685.

(7) Dickey, A. N.; Yazaydın, A. Ö.; Willis, R. R.; Snurr, R. Q. Screening $\mathrm{CO}_{2} / \mathrm{N}_{2}$ Selectivity in Metal-Organic Frameworks using Monte Carlo Simulations and Ideal Adsorbed Solution Theory. Can. J. Chem. Eng. 2012, 90, 825-832.

(8) Supronowicz, B.; Mavrandonakis, A.; Heine, T. Interaction of Small Gases with the Unsaturated Metal Centers of the HKUST-1 Metal Organic Framework. J. Phys. Chem. C 2013, 117, 14570-14578.

(9) Liu, Q.; Ning, L.; Zheng, S.; Tao, M.; Shi, Y.; He, Y. Adsorption of Carbon Dioxide by MIL-101(Cr): Regeneration Conditions and Influence of Flue Gas Contaminants. Sci. Rep. 2013, 3, 2916.

(10) Al-Janabi, N.; Hill, P.; Torrente-Murciano, L.; Garforth, A.; Gorgojo, P.; Siperstein, F.; Fan, X. Mapping the Cu-BTC Metal-Organic Framework (HKUST-1) Stability Envelope in the Presence of Water Vapour for $\mathrm{CO}_{2}$ Adsorption from Flue Gases. Chem. Eng. J. 2015, 281, 669-677.

(11) Cavenati, S.; Grande, C. A.; Rodrigues, A. E.; et al. Metal-Organic Framework Adsorbent for Biogas Upgrading. Ind. Eng. Chem. Res. 2008, 47, 6333-6335.

(12) Ge, L.; Wang, L.; Rudolph, V.; Zhu, Z. Hierarchically Structured Metal-Organic Framework/Vertically-aligned Carbon Nanotubes Hybrids for $\mathrm{CO}_{2}$ Capture. RSC Adv. 2013, 3, 25360-25366.

(13) Liu, J.; Wang, Y.; Benin, A. I.; Jakubczak, P.; Willis, R. R.; LeVan, M. D. $\mathrm{CO}_{2} / \mathrm{H}_{2} \mathrm{O}$ Adsorption Equilibrium and Rates on Metal-Organic Frameworks: HKUST-1 and Ni/DOBDC. Langmuir 2010, 26, 1430114307.

(14) Millward, A. R.; Yaghi, O. M. Metal-organic Frameworks with Exceptionally High Capacity for Sorage of Carbon Dioxide at Room Temperature. J. Am. Chem. Soc. 2005, 127, 17998-17999.

(15) Moellmer, J.; Moeller, A.; Dreisbach, F.; Glaeser, R.; Staudt, R. High Pressure Adsorption of Hydrogen, Nitrogen, Carbon Dioxide and Methane on the Metal-Organic Framework HKUST-1. Microporous Mesoporous Mater. 2011, 138, 140-148.

(16) Simmons, J. M.; Wu, H.; Zhou, W.; Yildirim, T. Carbon Capture in Metal-Organic Frameworks - A Comparative Study. Energy Environ. Sci. 2011, 4, 2177-2185.

(17) Wang, Q. M.; Shen, D.; Bulow, M.; Lau, M. L.; Deng, S.; Fitch, F.; Lemcoff, N. O.; Semanscin, J. Metallo-Organic Molecular Sieve for Gas Separation and Purification. Microporous Mesoporous Mater. 2002, 55, 217-230.

(18) Yazaydın, A. O.; Benin, A. I.; Faheem, S. A.; Jakubczak, P.; Low, J. J.; Willis, R. R.; Snurr, R. Q. Enhanced $\mathrm{CO}_{2}$ Adsorption in MetalOrganic Frameworks via Occupation of Open-Metal Sites by Coordinated Water Molecules. Chem. Mater. 2009, 21, 1425-1430.
(19) Chui, S. S.; Lo, S. M.-F.; Charmant, J. P. H.; Orpen, A. G.; Williams, I. D. A Chemically Functionalizable Nanoporous Material $\left[\mathrm{Cu}_{3}(\mathrm{TMA})_{2}\left(\mathrm{H}_{2} \mathrm{O}\right)_{3}\right]_{\mathrm{n}}$. Science 1999, 283, 1148-1150.

(20) Toda, J.; Fischer, M.; Jorge, M.; Gomes, J. R. B. Water Adsorption on a Copper Formate Paddlewheel Model of CuBTC: A Comparative MP2 and DFT study. Chem. Phys. Lett. 2013, 587, 7-13.

(21) Zang, J.; Nair, S.; Sholl, D. S. Prediction of Water Adsorption in Copper-Based Metal-Organic Frameworks Using Force Fields Derived from Dispersion-Corrected DFT Calculations. J. Phys. Chem. C 2013, 117, 7519-7525.

(22) Peng, X.; Lin, L. C.; Sun, W.; Smit, B. Water Adsorption in MetalOrganic Frameworks with Open-Metal Sites. AIChE J. 2015, 61 (2), $677-687$.

(23) Gul-E-Noor, F.; Michel, D.; Krautscheid, H.; Haase, J.; Bertmer, $\mathrm{M}$. Time dependent water uptake in $\mathrm{Cu}_{3}(\mathrm{btc})_{2}$ MOF: Identification of Different Water Adsorption States by ${ }^{1} \mathrm{H}$ MAS NMR. Microporous Mesoporous Mater. 2013, 180, 8-13.

(24) Huang, L.; Bandosz, T.; Joshi, K. L.; van Duin, A. C.; Gubbins, K. E. Reactive Adsorption of Ammonia and Ammonia/Water on CuBTC Metal-Organic Framework: A ReaxFF Molecular Dynamics Simulation. J. Chem. Phys. 2013, 138, 034102.

(25) Al-Janabi, N.; Alfutimie, A.; Siperstein, F.; Fan, X. Underlying Mechanism of the Hydrothermal Instability of $\mathrm{Cu}_{3}(\mathrm{BTC})_{2}$ MetalOrganic Framework. Front. Chem. Sci. Eng. 2016, 10, 103-107.

(26) Gul-E-Noor, F.; Jee, B.; Poppl, A.; Hartmann, M.; Himsl, D.; Bertmer, M. Effects of Varying Water Adsorption on a $\mathrm{Cu}_{3}(\mathrm{BTC})_{2}$ Metal-Organic Framework (MOF) as Studied by ${ }^{1} \mathrm{H}$ and ${ }^{13} \mathrm{C}$ Solid-State NMR Spectroscopy. Phys. Chem. Chem. Phys. 2011, 13, 7783-7788.

(27) Liang, Z.; Marshall, M.; Chaffee, A. L. $\mathrm{CO}_{2}$ Adsorption-Based Separation by Metal-Organic Framework (Cu-BTC) versus Zeolite (13X). Energy Fuels 2009, 23, 2785-2789.

(28) Cychosz, K. A.; Matzger, A. J. Water Stability of Microporous Coordination Polymers and the Adsorption of Pharmaceuticals from Water. Langmuir 2010, 26, 17198-17202.

(29) Schoenecker, P. M.; Carson, C. G.; Jasuja, H.; Flemming, C. J. J.; Walton, K. S. Effect of Water Adsorption on Retention of Structure and Surface Area of Metal-Organic Frameworks. Ind. Eng. Chem. Res. 2012, $51,6513-6519$.

(30) Low, J. J.; Benin, A. I.; Jakubczak, P.; Abrahamian, J. F.; Faheem, S. A.; Willis, R. R. Virtual High Throughput Screening Confirmed Experimentally: Porous Coordination Polymer Hydration. J. Am. Chem. Soc. 2009, 131, 15834-15842.

(31) DeCoste, J. B.; Peterson, G. W.; Schindler, B. J.; Killops, K. L.; Browe, M. A.; Mahle, J. J. The Effect of Water Adsorption on the Structure of the Carboxylate Containing Metal-Organic Frameworks Cu-BTC, Mg-MOF-74, and UiO-66. J. Mater. Chem. A 2013, 1, 1192211932.

(32) Cai, Y.; Zhang, Y.; Huang, Y.; Marder, S. R.; Walton, K. S. Impact of Alkyl-Functionalized BTC on Properties of Copper-Based MetalOrganic Frameworks. Cryst. Growth Des. 2012, 12, 3709-3713.

(33) Peikert, K.; Hoffmann, F.; Fröba, M. Fluorine magic: one new organofluorine linker leads to three new metal-organic frameworks. CrystEngComm 2015, 17 (2), 353-360.

(34) Peikert, K.; Hoffmann, F.; Fröba, M. Amino Substituted $\mathrm{Cu}_{3}(\text { btc })_{2}$ : A New Metal-Organic Framework with a Versatile Functionality. Chem. Commun. 2012, 48, 11196-11198.

(35) Cai, Y.; Kulkarni, A. R.; Huang, Y.-G.; Sholl, D. S.; Walton, K. S. Control of Metal-Organic Framework Crystal Topology by Ligand Functionalization: Functionalized HKUST-1 Derivatives. Cryst. Growth Des. 2014, 14, 6122-6128.

(36) Ko, N.; Hong, J.; You, L.; Park, H. J.; Yang, J. K.; Kim, J. Chemical Property Change in a Metal-Organic Framework by Fluoro Functionality. Bull. Korean Chem. Soc. 2015, 36, 327-332.

(37) Decoste, J. B.; Peterson, G. W.; Smith, M. W.; Stone, C. A.; Willis, C. R. Enhanced Stability of Cu-BTC MOF via Perfluorohexane PlasmaEnhanced Chemical Vapor Deposition. J. Am. Chem. Soc. 2012, 134, 1486-1489.

(38) Zhang, W.; Hu, Y.; Ge, J.; Jiang, H. L.; Yu, S. H. A Facile and General Coating Approach to Moisture/Water-Resistant Metal-Organic 
Frameworks with Intact Porosity. J. Am. Chem. Soc. 2014, 136, 1697816981.

(39) Luo, Q. X.; Song, X. D.; Ji, M.; Park, S. E.; Hao, C.; Li, Y. Q. Molecular Size- and Shape-Selective Knoevenagel Condensation over Microporous $\mathrm{Cu}_{3}(\mathrm{BTC})_{2}$ Immobilized Amino-Functionalized Basic Ionic Liquid Catalyst. Appl. Catal., A 2014, 478, 81-90.

(40) Hwang, Y. K.; Hong, D. Y.; Chang, J. S.; Jhung, S. H.; Seo, Y. K.; Kim, J.; Vimont, A.; Daturi, M.; Serre, C.; Ferey, G. Amine Grafting on Coordinatively Unsaturated Metal Centers of MOFs: Consequences for Catalysis and Metal Encapsulation. Angew. Chem., Int. Ed. 2008, 47, 4144-4148.

(41) Demessence, A.; D’Alessandro, D. M.; Foo, M. L.; Long, J. R. Strong $\mathrm{CO}_{2}$ Binding in a Water-Stable, Triazolate-Bridged MetalOrganic Framework Functionalized with Ethylenediamine. J. Am. Chem. Soc. 2009, 131, 8784-8786.

(42) Cao, Y.; Song, F.; Zhao, Y.; Zhong, Q. Capture of Carbon Dioxide from Flue Gas on TEPA-Grafted Metal-Organic Framework $\mathrm{Mg}_{2}$ (dobdc). J. Environ. Sci. 2013, 25, 2081-2087.

(43) Campbell, J.; Székely, G.; Davies, R. P.; Braddock, D. C.; Livingston, A. G. Fabrication of Hybrid Polymer/Metal Organic Framework Membranes: Mixed Matrix Membranes versus in situ Growth. J. Mater. Chem. A 2014, 2, 9260-9271.

(44) Kumar, S.; Rai, A. K.; Singh, V. B.; Rai, S. B. Vibrational Spectrum of Glycine Molecule. Spectrochim. Acta, Part A 2005, 61, 2741-2746.

(45) Dhumal, N. R.; Singh, M. P.; Anderson, J. A.; Kiefer, J.; Kim, H. J. Molecular Interactions of a Cu-Based Metal-Organic Framework with a Confined Imidazolium-Based Ionic Liquid: A Combined Density Functional Theory and Experimental Vibrational Spectroscopy Study. J. Phys. Chem. C 2016, 120, 3295-3304.

(46) Prestipino, C.; Regli, L.; Vitillo, J. G.; Bonino, F.; Damin, A.; Lamberti, C.; Zecchina, A.; Solari, P. L.; Kongshaug, K. O.; Bordiga, S. Local Structure of Framework $\mathrm{Cu}(\mathrm{II})$ in HKUST-1 Metallorganic Framework: Spectroscopic Characterization upon Activation and Interaction with Adsorbates. Chem. Mater. 2006, 18, 1337-1346.

(47) Herm, Z. R.; Bloch, E. D.; Long, J. R. Hydrocarbon Separations in Metal-Organic Frameworks. Chem. Mater. 2014, 26, 323-338.

(48) Myers, A. L.; Prausnitz, J. M. Thermodynamics of Mixed-Gas Adsorption. AIChE J. 1965, 11, 121-127.

(49) O’Brien, J. A.; Myers, A. L. Rapid Calculations of Multicomponent Adsorption Equilibria from Pure Isotherm Data. Ind. Eng. Chem. Process Des. Dev. 1985, 24, 1188-1191.

(50) Albrecht, G.; Corey, R. B. The Crystal Structure of Glycine. J. Am. Chem. Soc. 1939, 61, 1087-1103.

(51) Graham, C.; Pierrus, J.; Raab, R. E. Measurement of the Electric Quadrupole Moments of $\mathrm{CO}_{2}, \mathrm{CO}$ and $\mathrm{N}_{2}$. Mol. Phys. 1989, 67, 939955.

(52) Duren, T.; Snurr, R. Q. Assessment of Isoreticular Metal-Organic Frameworks for Adsorption Separations: A Molecular Simulation Study of Methane/n-Butane Mixtures. J. Phys. Chem. B 2004, 108, 1570315708 . 